\title{
HILLE AND NEHARI TYPE OSCILLATION CRITERIA FOR HIGHER ORDER DYNAMIC EQUATIONS ON TIME SCALES
}

\author{
Yizhuo Wang, Zhenlai Han AND ChuanXia Hou
}

Abstract. In this paper, we consider the higher order dynamic equation of the form

$$
\left(a(t)\left(r(t) x^{\Delta^{n-2}}(t)\right)^{\Delta}\right)^{\Delta}+p(t) x(t)=0, \quad t \geqslant t_{0}>0,
$$

where $n$ is an arbitrary positive integer with $n \geqslant 3, t$ is defined on an arbitrary time scale $\mathbb{T}$ with $\sup \mathbb{T}=\infty$. By Riccari transformation technique and comparison theorem, some Hille and Nehari type oscillation criteria are established. The main results are illustrated by examples.

Mathematics subject classification (2010): 34C10, 34K11.

Keywords and phrases: oscillation, higher order dynamic equation, time scales.

\section{REFERENCES}

[1] S. HiLger, Analysis on measure chains-a unified approach to countinuous and discrete calculus, Results Math. 18 (1990), 18-56.

[2] M. Bohner And A. Peterson, Dynamic Equation on Time Scales: An Introduction with Applications, Birkhäuser, Boston, 2001.

[3] G. D. BIRKHOFF, On solutions of ordinary linear homogeneous differential equations of the third order, Ann. of Math. 12 (1911), 103-127.

[4] C. N. REYNOLDS, JR., On the zeros of solutions of homogeneous linear differential equations, Trans. Amer. Math. Soc. 22 (1921), 220-229.

[5] I. T. KIGURADZE, Oscillatory properties of solutions of certain ordinary differential equations, Soviet Math. Dokl 3 (1962), 649-652.

[6] I. M. Glazman, Direct Methods of Qualitative Spectral Analysis of Singular Differential Operators (Israel Program for Scientific Translations). Davey, New York, 1965.

[7] I. M. GLAZMAN, Oscillation theorems for differential equations of high orders and the spectrum of the respective differential operators, Dokl. Akad. Nauk SSSR [N.S.] 118 (1958), 423-426.

[8] G. V. ANAN'EVA AND V. I. BALAGANSKII, Oscillation of the solutions of certain differential equations of high order, Uspehi Mat. Nauk 14, No. 1 (85) (1959), 135-140.

[9] A. KNESER, Untersuchungen uber die reelen Nullstellen der Integrale linearer Differentialgleichungen, Math. Ann. 42 (1893), 409-435; J. Reine Angew. Math. 116 (1896), 178-212.

[10] L. Erbe, A. Peterson And S. H. SAKer, Hille and Nehari type criteria for third-order dynamic equations, J. Math. Anal. Appl. 329 (2007), 112-131.

[11] S. H. SAKER, Oscillation of third-order functional dynamic equations on time scales, Sci. China Math. 54 (2011), 2597-2614.

[12] R. P. Agarwal, M. Bohner, T. Li AND C. ZHAng, Hille and Nehari type criteria for third-order delay dynamic equations, J. Difference Equ. Appl. 19 (2013), 1563-1579.

[13] M. Bohner And A. Peterson, Advances in Dynamic Equation on Time Scales, Birkhäuser, Boston, 2003.

[14] R. P. Agarwal, M. Bohner, Basic calculus on time scales and some of its applications, Results Math. 35 (1999), 3-22.

[15] T. ChantURIA, I. KiguradZE, Asymptotic properties of solutions of nonautonomous ordinary differential equations, Kluwer Academic Publisher, Dordrecht-Boston-London, 1993. 
[16] S. R. GRace, R. P. Agarwal, And A. ZAFer, Oscillation of higher order nonlinear dynamic equations on time scales, Adv. Difference Equ. 2012 (2012), Article ID 67, 1-18. 